International Journal of Applied Research 2021; 7(2): 136-138

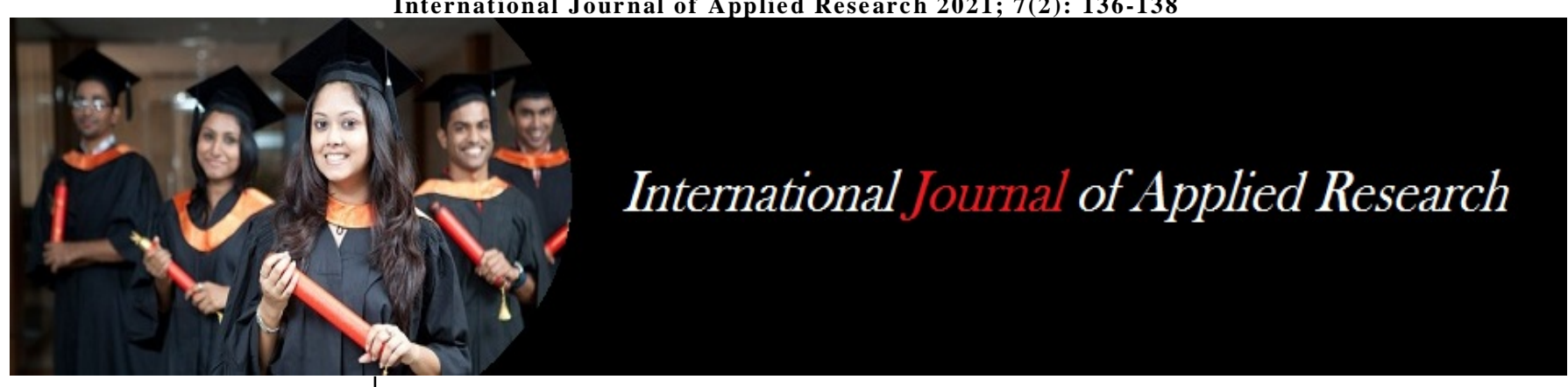

ISSN Print: 2394-7500

ISSN Online: 2394-5869

Impact Factor: 8.4

IJAR 2021; 7(2): 136-138

www.allresearchjournal.com

Received: 15-12-2020

Accepted: 01-01-2021

\section{राम बाबू चौपाल}

गवेषक, राजनीति विज्ञान विभाग ल० ना० मिथिला विश्वविद्यालय, दरभंगा, बिहार, भारत
Corresponding Author: राम बाबू चौपाल गवेषक, राजनीति विज्ञान विभाग ल० ना० मिथिला विश्वविद्यालय, दरभंगा, बिहार, भारत

\section{मिथिला राज्य की वास्तविकताः एक विश्लेषणात्मक अध्ययन}

\section{राम बाबू चौपाल}

\section{सारांश}

मिथिला क्षेत्र को अलग रूप से राज्य के रूप में अभिहीत करने हेतु मिथिलावासियों द्वारा प्रयास किया जा रहा है। इसके विभिन्न कारण हैं। भारत के दार्शनिक, उद्भव, सांस्कृतिक और साहित्यिक विकास के क्षेत्र में मिथिला का महत्वपूर्ण स्थान रहा है। मिथिला का इतिहास निस्संदेह गौरवमय रहा है. पुरातत्व के अवशेषों का अन्वेषण, विश्लेषण में पूरा पाषाणकाल, मध्यकाल और नव पाषाण काल के कई अवशेष अभीतक प्रकाश में नहीं आए हैं। इस पत्र के माध्यम से मिथिला राज्य की वास्तविकता पर विश्लेषण प्रस्तुत करने का प्रयास किया गया है।

मुख्य शब्द: मिथिला, नामकरण, मैथिल भाषी क्षेत्र, वास्तविक कारण, स्वतंत्रता संग्राम।

\section{प्रस्तावना:}

विदेह और मिथिला नामकरण का सर्वाधिक प्राचीन संबंध शतपथ ब्राह्मण में उल्लिखित विदेघ माथव से जुड़ता है। मिथिला के बसने के आरंभिक समय का संकेत उक्त कथा में प्राप्त होता है। विदेघ माथव तथा उसके पुरोहित गोतम राहूगण सरस्वती नदी के तीर से पूर्व की ओर चले थे। उनके आगे-आगे अग्नि वैथ्वानर नदियों का जल सुखाते हुए चल रहे थे। सदानीरा (गण्डकी) नदी को अग्नि सुखा नहीं सके और विदेघ माथव द्वारा यह पूछे जाने पर कि अब मेरा निवास कहाँ हो, अग्नि ने उत्तर दिया कि इस नदी के पूर्व की ओर तुम्हारा निवास हो। शतपथ ब्राह्मण में स्पष्ट रूपेण उल्लिखित है कि पहले ब्राह्मण लोग इस नदी को पार नहीं करते थे तथा यहाँ की भूमि उपजाऊ नहीं थी। उसमें दलदल बहुत था क्योंकि अग्नि वैथ्वानर ने उसका आस्वादन नहीं किया था। परंतु अब यह बहुत उपजाऊ है क्योंकि ब्राह्मणों ने यज्ञ करके उसका आस्वादन अग्नि को करा दिया है। गण्डकी नदी के बारे में यह भी उल्लेख है कि गर्मी के बाद के दिनों में भी, अर्थात् काफी गर्मी के दिनों में भी, यह नदी खूब बहती है। इस विदेघ शब्द से विदेह का तथा माथव शब्द से मिथिला का संबंध प्रतीत होता है। शतपथ में ही गंडकी नदी के बारे में उल्लेख करते हुए स्पष्ट रूप से विदेह शब्द का भी उल्लेख हुआ है। वहाँ कहा गया है कि अब तक यह नदी कोसल और विदह देशों के बीच की सीमा है; तथा इस भूमि को माथव की संतान (माथवा:) कहा गया है। ${ }^{1}$

वाल्मीकीय रामायण तथा विभिन्न पुराणों में मिथिला नाम का संबंध राजा निमि के पुत्र मिथि से जोड़ा गया है। न्यूनाधिक अंतरों के साथ इन ग्रंथों में एक कथा सर्वत्र प्राप्त है कि निमि के मृत शरीर के मंथन से मिथि का जन्म हुआ था। वाल्मीकीय रामायण में मिथि के वंशज के मैथिल कहलाने का उल्लेख हुआ है जबकि पौराणिक ग्रंथों में मिथि के द्वारा ही मिथिला के बसाये जाने की बात स्पष्ट रूप से कही गयी है। शब्दान्तरों से यह बात अनेक ग्रंथों में कही गयी है कि स्वतः जन्म लेने के कारण उनका नाम जनक हुआ, विदेह (देह-रहित) पिता से उत्पन्न होने के कारण वे वैदेह कहलाये तथा मंथन से उत्पन्न होने के कारण उनका नाम मिथि हुआ। इस प्रकार उन्हीं के नाम से उनके द्वारा शासित प्रदेश का नाम विदेह तथा मिथिला माना गया है। महाभारत में प्रदेश का नाम 'मिथिला' तथा इसके शासकों को 'विदेहवंशीय' (विदेहा:) कहा गया है। ${ }^{2}$

भारत में तो ऐसे-ऐसे राज्य है जो कि 8-10 जिला को मिलाकर राज्य बनाया गया है । जबकि मिथिला का मांग तो 28-30 जिला को एक करके माँग किया जा रहा है जिलाओं का अगर गिनती करे तो इस प्रकार है- मधुबनी, दरभंगा, सीतामढ़ी, शिवहर, सुपोल, अररिया, किशनगंज, पूर्णिया, मधेपुरा, सहरसा, कटिहार, समस्तीपुर, मुज़फ्फरपुर, बेगुसराय, खगरिया, वैशाली, भागलपुर, बांका, गोड्डा, साहेबगंज, पश्चिमी चम्पारण, पूर्वी चम्पारण, देवघर, दुमका, पाकुर, जामतारा, जमुई, लक्खीसराय और शेखसराय। मिथिला आज से नहीं वरन कई युगों से अपने नाम से जाने जानेवाली धरोहर है। ख़ास कर जो लोग हिन्दू धर्म से जुड़े है वह तो वेद, पुराण और रामायण जैसे ग्रन्थ में मिथिला नाम का जाप तो कर ही चुके हैं और कर ही रहे हैं। 
मिथिला के लोग जो कि बहुत ही सभ्य है जिसको ब्रिटिश इंडिया से लेकर स्वत्रंत भारत होने के के वावजूद भी किसी ने मिथिला के ऊपर उस दृष्टि से नहीं देखा, जिस तरह अन्य राज्यों को देखा गया।

आधुनिक समय में 1867 में प्रथम स्वतंत्रता संग्राम के बाद अंग्रेज देश को खंडित और कमजोर करने में काफी सक्रीय था । उसी समय नेपाल और ब्रिटिश इंडिया के बीच युद्ध भी हुआ था । इसी यद्ध (1814-1816) के बाद अंग्रेज अपनी सत्ता को सुदृढ़ करने के लिए 04 मार्च 1816 को सुगौली संधि किया, जिसमे भारत का मिथिला क्षेत्र का भू-भाग करीब पांच हज़ार वर्गमील नेपाल को दे दिया। ये संधि 'ईस्ट इंडिया कम्पनी और नेपाल का गोरखा राजा के बीच हुआ था। ये अन्याय तो आधुनिक समय में सबसे पहले अंग्रेज ने किया, और मिथिला कि तेजस्वी भूमि को दो देशो में विभक्त कर दिया, सम्भवतः उसको यहाँ से भागने में ये पाप भी सहायक हुआ होगा। नेपाल में जो मैथिली भाषी जिला है वो इस प्रकार है- परसा, बारा, रौतहत, सरलाही, महोत्तरी, धनौसा, सिरहा, सप्तारी, सुनसारी, मोरंग और झापा इसमें से कुछ जिला का भाग सुगौली संधि के समय ब्रिटिश इंडिया ने नेपाल को दे दिया था। उस समय भी एक भाषीय परिवार को अंगेज ने तोड़ कर दो टुकड़ा कर दिया। ये अन्याय भी मिथिलावासी बर्दास्त कर अंग्रेजो को भगाने में भारत को स्वतंत्रत करने और करवाने के लिए एकजुट हो स्वतंत्रता आंदोलन में कूद पड़े ताकि देश के और टुकड़े-टुकड़े अंग्रेज न कर सकें $\left.\right|^{3}$

1917 ई० में जो भी भारत का साहित्यिक भाषा था उसको अनिवार्य रूप से कलकत्ता विश्वविद्यालय के कुलपति स्वर्गीय सर आशुतोष मुखर्जी जी ने प्रतिष्ठित किया। जिसके परिणाम स्वरुप हिंदी, बंगला, मणिपुरी और आसामी के साथ-साथ मैथिली को भी मेट्रिक से लेकर स्नातक तक का विषय बनाया गया। साथ साथ मात्र पाँच साहित्यिक भाषा को एम० ए० का मुख्य विषय के रूप में स्वीकृति मिला जिसके मध्य मैथिली भी था। मैथिली कि अपनी लिपि भी है जिसे मिथिलाक्षर के रूप में जाना जाता है। मैथिली भाषा का बहुत ठोस आधार है। माना जाता है कि जिस भाषा का अपना लिपि अपना व्याकरण और अधिकाधिक बोला जाता हो उसी को ठोस भाषा के रूप स्थापित किया जाता है, जिसको सर्व प्रथम कलकत्ता विश्वविद्यालय द्वारा मातृभाषा के रूप सम्मानित किया जा चुका है। बंगला, मणिपुरी, आसामी सबको अपनाअपना राज्य मिल गया, पर शांत मिथिला न्यायिक ग्रन्थ लिखनेबाला मिथिला का किताब पढ़ दूसरों को अधिकार तो दे दिया गया परन्तु न्याय दर्शन पढ़कर भी मिथिला का उपेक्षा किया गया। ये कैसा न्याय है?

1920 ई० में कोंग्रेस का नागपुर अधिवेसन में राज्य निर्माण के लिए भाषा को प्राथमिक महत्व दिया गया और आगे चलकर इसी आधार पर कई राज्य बने भी जैसे उड़ीसा, आंध्रा प्रदेश, पश्चिम बंगाल, मद्रास वर्त्तमान का चेन्नई और आसाम तो प्रथम राज्य है जो कि भाषा के आधार पर ही बनाया गया। १६२९ ई० में असहयोग आंदोलन के फलस्वरूप जब राष्ट्रिय भावना का उद्भव हुआ उस समय हिंदी का खूब प्रचार किया जा रहा था। खास कर अंग्रेजी को बहिष्कार करने के लिए, जबकि हिंदी राष्ट्र भाषा का स्थान पा चुका था, फिर भी काका कालेलकर मैथिली भाषीय क्षेत्र दरभंगा में बिना धन्यबाद लिए ही अपना सम्भाषण मंच छोड़कर चले गए थे, सिर्फ इसलिए कि उन्होंने ये कह दिया था कि ये हिंदी भाषीय क्षेत्र है और उस पर उनको शांतिपूर्वक विरोध कर दिया गया था कि ये हिंदी भाषीय नहीं बल्कि मैथिली भाषीय क्षेत्र मिथिला है $\left.\right|^{4}$

सर जॉर्ज़ गियर्सन के माध्यम से भारत के सभी भाषा का सर्वेक्षण भी किया गया और उन्होंने सबसे पहला मैथिली व्याकरण का किताब भी लिखा जो कि 1927 ई० प्रकाशित था। परन्तु भाषाई आधार पर राज्य बनाने बाले भारतीय प्रतिनिधि को इस तरफ ध्यान कौन ले जाता? 1937 ई० में कलकत्ता के अधिवेशन में
इसी नीति को फिर से दोहराया भी गया परन्तु अभी तक मिथिला के तरफ किसी का ध्यान केंद्रित नही हो सका। 1947 ई० में भारत स्वतंत्र हो गया और 1950 से 1956 तक भाषा को मुख्य आधार मानते हुए कई राज्य बनाया गया। परन्तु मिथिला कहाँ? किसी ने भी इसका खोज-खबर नहीं लिया, इस बात को देखते हुए मिथिलावासी को काफी चोट पहुंचा और $1950-1952$ आते-आते छोटा-मोटा आंदोलन होने लगा।

1972-73 में जब डॉ अमर नाथ झा बिहार लोकसेवा आयोग का अध्यक्ष बने तब मैथिली को आयोग का एक विषय के रूप में प्रस्ताव का स्वीकृति हुआ। लेकिन ये प्रस्ताव तब तक स्वीकृत प्रस्ताव रहा जब तक स्वर्गीय ललित नारायण मिश्र के भारत में प्रतिष्ठा का उदय नहीं हुआ था। उस समय का मुख्य मंत्री स्वर्गीय केदार पाण्डेय जी थे और उन्ही के अथक प्रयास से मैथिली का एक मुख्य केंद्र मिथिला विश्वविद्यालय का स्थापना किया गया साथ ही लोकसेवा आयोग में मैथिली एक ऐच्छिक विषय के रूप में आरम्भ किया गया। फिर 2003 में भारत के पूर्व प्रधान मंत्री माननीय अटल बिहारी वाजपेयी जी ने मैथली आंदोलन को स्वीकार किया और मैथिली को संविधान की अष्टम सूचि में स्थान देकर मिथिलावासी के ऊपर बड़ा ही उपकार किया ${ }^{5}$

मिथिला राज्य आंदोलन की मुख्य भूमिका 'अंतर्राष्ट्रीय मैथिली परिषद्,' मिथिला राज्य निर्माण सेना और 'संयुक्त मिथिला राज्य संघर्ष समिति' कर रही है जब से 'मिथिला राज्य निर्माण सेना' ने मिथिला राज्य का आंदोलन में अपना कदम बढ़ाया है ये आंदोलन जन जन तक आग की लपट की तरह फ़ल रहा है। वो दिन दूर नहीं जब मिथिलावासी अपना 'मिथिला' राज्य यथा सम्भव शीघ्र ही देख पाएंगे। बिहार सरकार के साथ-साथ भारत सरकार भी मिथिला क्षेत्र के तरफ अपना ध्यान हटा चुका है, जिसके फलस्वरूप कई समस्या बढ़ गई, कुछ नया समस्या सामने आया और कुछ पौराणिक ऐतिहासिक चीजे विलुप्त हो गई और होने के कगार पर है। जिसको बचाने के लिए मिथिलावासी को मिथिला राज्य के अलावा और कोई चारा दिखाई नहीं दे रहा है। मिथिला राज्य की मांग सिर्फ भाषा के आधार पर ही नहीं किया जा रहा है बल्कि इसके और भी बहुत आधार है जैसे- संवैधानिक अधिकार सम्पन्नता के लिए, संस्कृति और सभ्यता का संरक्षण के लिए, विशिष्ट पहचान 'मैथिल' का संरक्षण के लिए, पलायन और प्रवासी होने का खतरा से मिथिला का रक्षा के लिए, आर्थिक पिछडापण और उपेक्षा विरुद्ध स्वराज्यसम्पन्न विकास के लिए, स्वरोजगार संयंत्र-उन्नत कृषि-औद्योगिक विकास के लिए, बाढ़ का स्थायी उपचार के लिए, शिक्षा का गिरता स्तर में सुधार लिए, मुफ्त शिक्षा और शत्-प्रतिशत् साक्षरता के लिए, गरीबी उन्मुलन -हर व्यक्ति के लिए रोजी-रोटी और वस्त्र लिए, जातिवादिता का आग से जल रहे समाज में सौहार्द्रता के लिए, ऐतिहासिक संपन्नता प्राप्त धरोहर का संरक्षण के लिए, पर्यटन केन्द्र का स्थापना, विकास और संरक्षण के लिए, जल-स्रोत का समुचित बहाव को व्यवस्थित करने के लिए, मिथिला विशेष कृषि उत्पाद का व्यवसायीकरण के लिए, जल-विद्युत परियोजना-जल संचार परियोजना के लिए, मिथिला विशेष शिक्षा पद्धति (तंत्र और कर्मकाण्ड सहित अन्य कला) का अध्ययन केन्द्र के लिए, पौराणिक मिथिला देश के समान आर्थिक संपन्नता के लिए, पौराणिक न्याय प्रणाली समान उन्नत सामाजिक न्याय व्यवस्था के लिए, जन-प्रतिनिधि द्वारा वचन और कर्म में एकता के लिए, भ्रष्ट और सुस्त-निकम्मा प्रशासन तथा जनविरोधी शोषण को दमन करने के लिए, मुफ्त बिजली, पेयजल, शौच, गंदगी का बहाव व्यवस्थापन के लिए, मिथिला दूसरे देश के सीमावर्ती क्षेत्र होने के कारण विशेष सुरक्षा के लिए, मिथिला में कई बड़े बड़े नदी है महानंदा, कोसी, गंडक, कमला बलान, बूढी गंडक, गंगा इस नदी का भी नुकसान के अलाबा फायदा नहीं हुआ, इतनी नदियां होने 
के बादजूद हम बिजली पानी कि समस्या से परेशान है, इसलिए इन सबकी रक्षा और इनसे सुरक्षा के लिए।

\section{निष्कर्ष}

1912 में जब बिहार बंगाल प्रोविंस से निकल कर एक अलग स्टेट बना, उसी समय से एक अलग मिथिला स्टेट की मांग शुरू हो गई थी, तब से लेकर अब तक बिहार राज्य से निकलकर 1936 में ओडिशा और 2000 में झारखंड अलग राज्य बन चुके हैं। वहीं दूसरी तरफ अलग मिथिला राज्य की मांग चलती रही। आज समय की मांग एवं वास्तविक स्थितियों को देखते हुए आवश्यक है कि मिथिला क्षेत्र को अलग राज्य का दर्जा देकर प्रतिष्ठित किया जाय।

\section{संदर्भ}

1. ठाकुर, उपेन्द्र, 1956, हिस्ट्री ऑफ मिथिला, मिथिला इंस्टीच्यूट ग्रंथमाला 3 स्टडीज नं.-1

2. विद्यापति (सं. म. म. हर प्रसाद शास्त्री), 1924, कीर्ति पताका, बिहार हिन्दी ग्रंथ अकादमी, पटना-3

3. सिंह, एस.एन. 1922, हिस्ट्री ऑफ तिरहुत फ्रोम द एंसियेंट टाइम, कलकत्ता

4. शर्मा, राम प्रकाश, 1979, मिथिला का इतिहास, कामेश्वर सिंह दरभंगा संस्कृत विश्वविद्यालय, दरभंगा

5. चौधरी, राधाकृष्ण : मिथिला इन दि एज ऑफ विद्यापति, चौखम्बा संस्कृत सीरीज, वाराणसी 